\title{
The Malawi Orthopaedic Association/AO Alliance guidelines and standards for open fracture management in Malawi: a national consensus statement
}

\author{
Alexander Thomas Schade ${ }^{1}$, Master Yesaya ${ }^{2}$, Jeremy Bates ${ }^{2}$, Claude Martin Jr. ${ }^{3}$, William James \\ Harrison $^{3,4}$
}

1. University of Warwick Medical School, Coventry, UK

2. Queen Elizabeth Central Hospital, Blantyre, Malawi

3. AO Alliance, Davos, Switzerland

4. Countess of Chester Hospital NHS Trust, Chester, UK

Correspondence: Alexander Thomas Schade (alexander.T.schade@warwick.ac.uk)

\begin{abstract}
Background
\section{Abstract}

Open fractures are common injuries in Malawi that pose a large burden on the healthcare system and result in long-term disability. Aim

Establishing a multiprofessional agreement on the management of open fractures in Malawi from a consensus meeting.

Methods

AO Alliance convened a consensus meeting to build an agreement on the management of open fractures in Malawi. Eighteen members from different professions and various regions of Malawi participated in a 1-day consensus meeting on 7 September 2019. Prior to the meeting the British Orthopaedic Audit Standards for Trauma (BOAST) for open fractures, as well as relevant systematic reviews and seminal literature were circulated. Panel members gave presentations on open fracture management, followed by an open discussion meeting. At the 1-day consensus meeting panel members developed statements for each standard and guideline. Panel members then voted to accept or reject the statements.

Results

Substantial agreement (no rejections) was reached for all 17 guidelines and the associated terminology was agreed on. These guidelines were then presented to the members of the Malawi Orthopaedic Association (MOA) at their annual general meeting on 28 September 2019 and all participants agreed to adopt them.

Conclusions

These MOA/AO Alliance guidelines aim to set a standard for open fracture management that can be regularly measured and audited in Malawi to improve care for these patients.

Key Words
\end{abstract}

Open fractures, multiprofessional treatment, consensus meeting

\section{Introduction}

Open fractures are an increasingly common injury following road traffic accidents in Malawi ${ }^{1}$. They have a devastating impact on patients and their families, including $15 \%$ amputations, $18 \%$ infection and 15\% non-unions ${ }^{2}$. Some countries have established different standards of management for lower limb open fractures ${ }^{3,4}$ to provide an evidence-based approach to improve the management of these difficult injuries. The introduction of guidelines has led to improved patient outcomes including fewer procedures, reduced infection and reduced complications ${ }^{5,6}$. The BOAST standards are widely publicised and regularly audited by specialist centres in the United Kingdom. Due to resource limitations these guidelines cannot overall be applied to Malawi. The WHO has produced some guidelines for essential trauma but this includes very little information open fracture management ${ }^{7}$ and none exist for Malawi ${ }^{8}$. The Malawi Orthopaedic Association (MOA) is an organisation dedicated to improving and representing orthopaedic care in Malawi. AO Alliance is a developmental non-profit organisation dedicated to improving care of the injured in low- and middle-income countries through education, research, policy and awareness. To guide patients, clinicians and funders, we convened a consensus meeting. Our aim was to reach a multiprofessional agreement on the management of open fractures in Malawi.

\section{Methods}

The methodology is based on a consensus development conference ${ }^{9,10}$. In brief, the format involves an open meeting where evidence is presented by various interest groups who are not members of the decision-making group. The latter then retire to consider the questions in the light of the evidence presented and attempt to reach consensus. The group members are encouraged to ask questions and the chairperson is responsible for controlling the proceedings; members of the public can also participate in the discussion.

\section{Panel selection}

A range of members was invited from various orthopaedic professions and different regions of Malawi. Eleven 
orthopaedic surgeons, one theatre matron, four orthopaedic clinical officers (OCOs), one medical intern and one project officer were included. We invited people who were known to have a research interest and clinical practice in managing open fractures in Malawi. Various regions in Malawi were represented, therefore, we had one member from the northern region, three members from the central region, seven members from the southern region and four international members.

\section{Preliminary work}

We developed a list of topics and questions that we hope to answer, circulating ideas around the panel until there was agreement. The BOAST guidelines ${ }^{3,4}$ were sent to all the panel members, who were asked to comment on each guideline. We also searched relevant databases (PubMed and Cochrane Library) using the search term 'open fracture guidelines' for published articles relevant to these topics from inception to 23 August 2019. A list of articles consisting of recent systematic reviews and original seminal research relevant to these topics was prepared; panel members also suggested additional articles where important research had been omitted.

\section{Agreement meeting}

On 7 September 2019, the panel met to formulate the agreement statement. ATS and WJH gave presentations on consensus methodology and the highest level of evidence for each guideline based on systematic reviews, randomised controlled trials and cohort studies. The meeting was chaired by WJH who did not express his opinion during the discussion. For each guideline, the chair facilitated a structured discussion leading to a proposed wording for consideration. Panel members then voted on each guideline expressing whether they accepted it, rejected it or abstained. Discussion and modification continued until there were no more rejections.

\section{Malawi Orthopaedic Association annual general meeting}

The members of the previous agreement meeting did not participate in voting at the MOA annual general meeting (AGM) meeting. On 28 September 2019, ATS and MY presented evidence on the latest open fracture management and the guidelines from the $\mathrm{AO}$ Alliance agreement meeting. The MOA AGM consisted of 65 OCOs and all members voted to adopt these guidelines as the joint $\mathrm{MOA} / \mathrm{AO}$ Alliance guidelines. OCOs are non-physician clinicians who specialize in non-operative care, manage $80-90 \%$ of orthopaedic trauma capacity and provide the highest level of orthopaedic expertise in district hospitals ${ }^{11}$. A representative of the Malawi Ministry of Health was also present, but did not vote, as he was not a MOA member.

\section{Results}

The complete guidelines are summarised in Appendix A.

\section{Discussions}

In the following paragraphs, we present the agreed statement for each guideline, followed by a summary of the panel's discussions. Before discussing the guidelines, the remit was stated as 'These guidelines are for all patients with open fractures of long bones, hind foot or midfoot (excluding hand, wrist, forefoot or digit). Grading refers to the GustiloAnderson classification ${ }^{12}$ ? Despite poor interobserver reliability ${ }^{13}$, the Gustilo-Anderson grading is still the most commonly used classification in Malawi. All panel members agreed on this.

1. Primary (A, B, C assessment) and secondary survey, according to ATLS/PTC, must precede the treatment of open fractures.

16 members agreed with this statement.

The first guideline is to emphasise the need to treat more lifethreatening injuries before the treatment of open fractures. Airway, breathing, circulation (ABC) assessment was decided by members to be easily understood as the primary survey. We felt it important to include primary trauma care (PTC) assessment as this course is more commonly learnt by practitioners in central and district hospitals in Malawi ${ }^{14}$ than Advanced Trauma Life Support (ATLS). PTC has led to reduced deaths and disability as well as improved staffing, equipment and training at healthcare facilities. ${ }^{15}$

2. Intravenous prophylactic antibiotics should be administered as soon as possible and at least within 1 hour of presentation to the health facility:

a. Intravenous ceftriaxone (at appropriate doses for age and weight).

b. Alternatively, oral doxycycline \& intravenous gentamicin (if no ceftriaxone is available).

c. For grossly contaminated wounds, in addition, administer intravenous metronidazole.

d. If none available, give the most appropriate available antibiotics.

15 members agreed with this statement, 1 member abstained.

The administration of antibiotics is associated with reduced rates of infectionand has been reviewed elsewhere ${ }^{16}$. Currently, there is no consensus on which antibiotic to administer or for what duration ${ }^{17}$. Opinion from a microbiology consultant in Malawi was sought and advised that the antibiotics suggested in the guideline would be appropriate for the management of open fractures in Malawi. These antibiotics are also applicable to children at the right doses depending on weight and age. The evidence suggests cephalosporins are appropriate for open fracture infection prevention, of which ceftriaxone is a third generation ${ }^{16}$. There was agreement amongst most panel members that ceftriaxone was available in their centre and this is also reported in the literature ${ }^{18}$. Currently, there is low resistance to ceftriaxone amongst coliforms in Blantyre, but there is some suggestion that this is rapidly increasing ${ }^{19}$. As an alternative, we agreed that oral doxycycline was more available in Malawi than flucloxacillin. Some suggest that oral antibiotics are non-inferior to intravenous antibiotics for complex orthopaedic infections ${ }^{20}$, but the panel felt antibiotics should be given intravenously, if possible. We also agreed that giving any antibiotic that was available was better than no antibiotic. There was some concern whether giving oral antibiotics would cause delay in debridement due to the nil-by-mouth status. We agreed that oral antibiotics should be continued in the perioperative period and can be given with sips of water, even if the patient is nil by mouth ${ }^{21}$. 
3. The examination of the injured limb should include assessment and documentation of the vascular and neurological status. This should be repeated systematically, particularly after reduction manoeuvres and/or the application of splints or casts.

16 members agreed with this statement.

This guideline was not controversial and quickly agreed by all panel members.

4. Grade III C fractures with an ischaemic limb should be discussed immediately with the central hospital by telephone with a view to immediate referral when appropriate.

16 members agreed with this statement.

Vascular injury should be managed by multidisciplinary teams in central hospitals to ensure re-establishment of circulation within 3-4 hours of injury to avoid irreversible complications such as muscle damage, renal failure and death $^{22}$.

5. The limb must be re-aligned and splinted or casted before transfer to the ward or another health facility.

16 members agreed with this statement.

This guideline was not controversial and quickly agreed by all panel members.

6. Prior to formal debridement the wound should be exposed only to remove gross contamination and to allow photography, then dressed with a sterile saline-soaked gauze. 16 members agreed with this statement.

The panel agreed that the wounds should not be repeatedly exposed, ideally only once. The use of antiseptic gauze does not have any beneficial effect ${ }^{23}$, but the gauze should be sterile.

7. Washouts outside the operating theatre environment are not indicated and patients should be prepared for debridement under spinal or general anaesthetic.

16 members agreed with this statement.

We widely felt that debridement should be done under spinal or general anaesthetic, which is based on evidence from military surgery ${ }^{24}$. The evidence suggests that there is no benefit to washouts outside the operating room; multiple debridements are associated with worse outcomes in animal models and can also make referrals more ambiguous ${ }^{25,26}$.

8. Debridement should be performed, under general or spinal anaesthetic, using fasciotomy lines for wound extension where possible: a. Immediately for highly contaminated wounds (agricultural, aquatic, sewage) or when there is an associated vascular compromise (compartment syndrome or arterial disruption producing ischaemia).

b. Within 12 hours of presentation to hospital for grade II \& III fractures.

c. Within 24 hours of presentation to hospital for grade I fractures.

15 members agreed with this statement, 1 member abstained.

Most of the current studies show that there is no benefit to performing debridement within 6 hours of injury (except for highly contaminated, compartment syndrome and arterial injury) compared with 24 hours in terms of infection, time to union, non-union rates, number of surgical procedures, admissions, time in hospital, time to weight bearing, walking speed and time to return to work $^{27}$. Most of the current evidence suggests no difference in major infective complications between 12 hours and 24 hours $^{28}$.

9. Before prepping and draping the patient, contamination is removed with at least 5L of tap water. At debridement, all devitalised soft tissue and bone should be removed, both bone ends exposed, further irrigation with at least $2 \mathrm{~L}$ of sterile fluid.

15 members agreed with this statement, 1 member abstained.

The type of fluid and whether to use pulse lavage remains controversial $^{29}$, but the panel agreed that high volumes are crucial. A Cochrane review argued that there is no evidence that the use of tap water for acute wounds increases infection, and actually might decrease $\mathrm{it}^{30}$.

10. Photographs of the wound should be taken at first presentation to the health facility and after debridement.

16 members agreed with this statement.

Patient confidentiality should be maintained and photography should be undertaken within the framework of national guidelines for health information. Different health technologies are being developed to improve compliance with storing photographs securely ${ }^{31}$.

11. Once debridement is complete any further procedures (e.g. external fixation) carried out at that same sitting should be regarded as clean surgery; i.e. there should be fresh instruments and a re-preparation and draping of the limb before proceeding.

16 members agreed with this statement.

This guideline was not controversial and quickly agreed by all panel members. 


\section{Clean grade I fractures should be closed primarily.}

Grade II fractures should be left open and closed within 72 hours.

Grade III A \& B fractures should be left open and referred to the nearest central hospital within 24 hours to enable wound closure or flap within 72 hours. This should include a letter and before and after debridement photographs to the receiving surgeon.

\section{5 members agreed with this statement, 1 member abstained.}

Grade I injuries, after debridement, can be safely closed with simple sutures and internal fixation with low rates of infection $^{32}$. Definitive soft tissue coverage within 3 days is associated with decreased infection and increased levels of fracture union $^{33-35}$. For complex fractures such as Gustilo III A \& B fractures, the evidence suggests that these should be managed in specialist centres where designated multidisciplinary teams with sufficient case volume and expertise are available to focus on these injuries ${ }^{36}$.

13. Long bone grade III A \& B fractures should be stabilised with an external fixator at the time of debridement. In some cases, an orthopaedic surgeon may use internal fixation.

16 members agreed with this statement.

The panel agreed that an external fixator should be applied when immediate wound cover and definitive stabilisation is not possible at debridement. Exchange from an external fixator to internal fixation, if undertaken, should be done as soon as possible. Internal fixation is safe if there is minimal contamination and it is done by an orthopaedic surgeon who can cover the wound with soft tissue at the same time as insertion of the implant $\mathrm{t}^{32}$.

14. Definitive internal stabilisation should only be carried out when it can be immediately followed with definitive soft tissue cover. Approximation sutures over exposed bone should not be done.

16 members agreed with this statement.

All members agreed that internal stabilisation should only be carried out when soft coverage is possible ${ }^{32}$. It was also noted that approximation sutures have been seen in Malawi and should not be done as they frequently cause ischaemia.

15. Immediate amputation, except in life-threatening emergency, should not be undertaken without consultation with another surgical colleague.

\section{6 members agreed with this statement.}

Primary amputation may be required as damage-control surgery for conditions such as uncontrollable haemorrhage, resuscitation or prolonged crush injuries. Early (within 48 hours) amputation may be appropriate for an unsalvageable limb. This decision should be taken by two surgeons not only so that the patient and their family feel reassured that a second opinion has been sought, but also for the operating surgeon to confirm their irreversible decision.
16. Patients should receive an explanation about their injury, the treatment and their functional outcome.

16 members agreed with this statement.

This statement implies that if the patient is a minor, their parents/guardian should be counselled. The patient must be advised regarding the serious nature of their injury and given expectations of prognosis and treatment in a way that they can understand.

17. Written notes in the medical records should provide evidence of the application of these guidelines.

\section{6 members agreed with this statement.}

Most of these guidelines should be documented in the medical notes as part of good medical practice, but all members agreed that this should be reiterated for the guidelines to be audited in the future.

\section{Limitations}

Firstly, our consensus group did not include members who work in district hospitals. This could limit the applicability of these guidelines to the district hospital setting; however, our panel members had experience in visiting district hospitals. District hospitals manage $80-90 \%$ of the orthopaedic clinical workload in Malawi ${ }^{37}$. Others have shown that ATLS training is currently sub-optimal in district hospitals, with less than $50 \%$ of front line trauma care providers receiving training in district hospitals ${ }^{38}$. Nevertheless, our guidelines were validated at the MOA AGM, which consists mostly of orthopaedic clinical officers working in district hospitals.

Secondly, this study was not able to comment on the availability of resources and the clinical knowledge of providers. Others have recently suggested a list of essential fracture and orthopaedic equipment for district and tertiary centres $^{39}$. In Malawi, the current capacity of hospitals to manage traumatic injuries is significantly limited, with only $20 \%$ of district and $49 \%$ of referral hospitals reporting adequate instruments for the surgical treatment of fractures ${ }^{37}$. Even electricity and running tap water may be limited as central and district hospitals experience a period of no running tap water $^{40}$. The guidelines aim to provide a realistic standard to aspire to in Malawi. It is hoped that the auditing of these standards in hospitals can be used as evidence for mobilisation of orthopaedic equipment and infrastructure to where it is most needed.

Thirdly, district hospitals commonly rely on general surgeons and OCOs to perform orthopaedic operations ${ }^{41}$. Training non-specialists like general surgeons and OCOs in open fracture management is critical to improving care delivery. Efforts should focus on continuing medical education in Malawi aimed at OCOs, particularly at events such as the MOA AGM. We included orthopaedic clinical officers and a microbiologist but did not include general or plastic surgeons. When revising these guidelines in the future, input and teaching from general surgeons and plastics surgeons would be valuable.

Finally, implementation of these guidelines will be key to ensure they have an effect on patient outcomes. Indeed, surgical bundles can be implemented in low-income countries to improve patient outcomes ${ }^{42,43}$. Dissemination of the guidelines should be accompanied by education, training and Https://dx.doi.org/10.4314/mmj.v32i3.2 


\section{AO Alliance consensus group (16 members and 2 moderators)}

\begin{tabular}{|c|c|c|c|c|c|}
\hline Region & Hospital & Name & Role & $\begin{array}{l}\text { Experience of } \\
\text { treating open } \\
\text { fractures }\end{array}$ & $\begin{array}{l}\text { Active in } \\
\text { Malawi }\end{array}$ \\
\hline Northern & $\begin{array}{l}\text { Muzuzu Central Hospital } \\
\text { Central government } \\
\text { hospital, Mzuzu, } 322 \text { beds, } \\
\begin{array}{l}\text { catchment population } 1.7 \\
\text { million }\end{array}\end{array}$ & Dr Boston Munthali & $\begin{array}{l}\text { Orthopaedic } \\
\text { consultant }\end{array}$ & $>10$ years & $\mathrm{Y}$ \\
\hline \multirow[t]{4}{*}{ Central } & $\begin{array}{l}\text { Kamuzu Central Hospital } \\
\text { Central government } \\
\text { hospital, Lilongwe (capital), } \\
800 \text { beds, catchment } \\
\text { population } 4 \text { million }\end{array}$ & Dr Leonard Banza & $\begin{array}{l}\text { Orth op a e d ic } \\
\text { consultant }\end{array}$ & $>10$ years & $\mathrm{Y}$ \\
\hline & & Mr George Manjolo & Senior OCO & $>10$ years & $\mathrm{Y}$ \\
\hline & & Mr Mabvuto Chawinga & Senior OCO & $>10$ years & $\mathrm{Y}$ \\
\hline & & Mr Precious Kamange & \begin{tabular}{|l}
$\begin{array}{l}\text { Malawi } \\
\text { officer }\end{array}$ \\
\end{tabular} & NA & $\mathrm{Y}$ \\
\hline \multirow[t]{10}{*}{ Southern } & $\begin{array}{l}\text { Zomba Central Hospital } \\
\text { Central government } \\
\text { hospital, Zomba, } 600 \text { beds, } \\
\text { catchment population } 4 \\
\text { million }\end{array}$ & Dr Olaf Bach & $\begin{array}{l}\text { Orthop a edic } \\
\text { consultant }\end{array}$ & $>10$ years & $\mathrm{Y}$ \\
\hline & $\begin{array}{l}\text { Queen Elizabeth Central } \\
\text { Hospital } \\
\text { Central government } \\
\text { hospital, Blantyre, } 1000 \\
\text { beds, catchment population } \\
1 \text { million }\end{array}$ & Mr Master Yesaya & Senior OCO & $>10$ years & $\mathrm{Y}$ \\
\hline & & Mr Chris Ngulube & Senior OCO & $>10$ years & $\mathrm{Y}$ \\
\hline & & Dr Jes Bates & $\begin{array}{l}\text { Orthopaedic } \\
\text { consultant }\end{array}$ & $>10$ years & $\mathrm{Y}$ \\
\hline & & Dr Linda Chokotho & $\begin{array}{l}\text { Orthopaedic } \\
\text { consultant }\end{array}$ & $>10$ years & $\mathrm{Y}$ \\
\hline & & Dr Chiku Mpanga & $\begin{array}{l}\text { Orthopaedic } \\
\text { consultant }\end{array}$ & $>10$ years & $\mathrm{Y}$ \\
\hline & & Ms Jana Schweder & $\begin{array}{l}\text { Visiting } \\
\text { medical intern }\end{array}$ & NA & $\mathrm{N}$ \\
\hline & $\begin{array}{l}\text { CURE Hospital Malawi } \\
\text { Orthopaedic } \\
\text { non-governmental } \\
\text { organisation, } 58 \text { beds }\end{array}$ & Ms Forcina Mdala & Theatre matron & $>10$ years & $\mathrm{Y}$ \\
\hline & & Dr Sam Maina & $\begin{array}{l}\text { Orthopaedic } \\
\text { consultant }\end{array}$ & $>10$ years & $\mathrm{Y}$ \\
\hline & & Dr Nicholas Lubega & $\begin{array}{l}\text { Orthopaedic } \\
\text { consultant }\end{array}$ & $>10$ years & $\mathrm{Y}$ \\
\hline \multirow[t]{2}{*}{ International } & AO Alliance & Dr Claude Martin & $\begin{array}{l}\text { Orthopaedic } \\
\text { consultant and } \\
\text { managing } \\
\text { director }\end{array}$ & $\begin{array}{l}>15 \text { years (other } \\
\text { low-income } \\
\text { countries) }\end{array}$ & $N$ \\
\hline & & $\begin{array}{l}\text { Prof Jim Harrison (non- } \\
\text { voting) }\end{array}$ & $\begin{array}{l}\text { Orthopaedic } \\
\text { consultant and } \\
\text { associate } \\
\text { professor }\end{array}$ & $>10$ years & $\mathrm{N}$ \\
\hline
\end{tabular}

feedback ${ }^{43}$. As these guidelines are implemented, it is hoped they will be refined as challenges will be encountered. These guidelines are merely a starting point for discussion and updating. We would encourage each department to audit their practice against these guidelines and share their findings locally and nationally.

\section{Conclusions}

We provide a multiprofessional agreement statement on the management of open fractures in Malawi. Key messages are summarised in Appendix A and include early intravenous antibiotics, initial debridement at least within 24 hours and definitive soft tissue coverage within 72 hours of healthcare 
facility presentation. We hope application of these standards and guidelines will help improve the management of this devastating injury in Malawi. We encourage units to audit their performance against the standards in their ongoing efforts to improve patient care.

\section{Authors' contributions}

Mr Alexander Thomas Schade BSc MBBS MRCS, University of Warwick, designed the study, collected the data, and wrote the manuscript.

Mr Master Yesaya BSc, Queen Elizabeth Central Hospital, helped with conception of the study and edited the manuscript.

Dr Jes Bates MBBS FRCS, Queen Elizabeth Central Hospital, helped with conception of the study and edited the manuscript.

Dr Claude Martin, AO Alliance, Davos, Switzerland helped with conception and edited the manuscript.

Prof William J Harrison MBBS FRCS, Countess of Chester Hospital, helped with conception, study design and edited the manuscript.

\section{Acknowledgements}

We would like to acknowledge Mr Kamange for organising the consensus meeting; Prof Andrew Metcalfe and $\mathrm{Mr}$ Edward Dickenson for advising on the methodology for the consensus meeting; Prof Nick Feasey, microbiology consultant at the Malawi-Liverpool-Wellcome centre for his advice on choice of antibiotics for open fractures in Malawi.

\section{Ethics}

No ethical approval was requested as this was a consensus meeting. Verbal consent was gained from all participants for manuscript publication.

\section{Funding}

We would like to thank AO Alliance for providing funds for the consensus meeting and the MOA conference.

\section{References}

1. Young S, Banza L, Munthali BS, Manda KG, Gallaher J, Charles A. The impact of the increasing burden of trauma in Malawi on orthopedic trauma service priorities at Kamuzu Central Hospital. Acta Orthop. 2016;87(6):632-6.

2. Schade AT, Hind J, Khatri C, Metcalfe AJ, Harrison WJ. Systematic review of patient reported outcomes from open tibia fractures in low and middle income countries. Injury. $2020 \mathrm{Feb} ; 51(2): 142-6$.

3. BOAST-4: open fractures. [cited 2019 Aug 1]. Available from: https://www.boa.ac.uk/resources/boast-4-pdf.html.

4. Nanchahal JN, Khan S, Moran U, Barrett C, Sanderson S, Pallister F.I. Standards for the management of open fractures of the lower limb. London: Royal Society of Medicine Press; 2009.

5. Trickett RW, Rahman S, Page P, Pallister I. From guidelines to standards of care for open tibial fractures. Ann R Coll Surg Engl. 2015;97(6):469-75. doi: 10.1308/rcsann.2015.0020.

6. Wordsworth M, Lawton G, Nathwani D, Pearse M, Naique S, Dodds A, et al. Improving the care of patients with severe open fractures of the tibia. Bone Joint J. 2016;98-B(3):420-4.

7. World Health Organization. Global status report on road safety. Geneva: WHO; 2015.

8. MoH, 2009, Malawi Standard Treatment Guidelines, Fourth Edition.

9. Black N, Murphy M, Lamping D, McKee M, Sanderson C, Askham $\mathrm{J}$, et al. Consensus development methods: a review of best practice in creating clinical guidelines. J Health Serv Res Policy. 1999;4:236-48.

10. Murphy MK, Black NA, Lamping DL, McKee CM, Sanderson CFB, Askham J, et al. Consensus development methods, and their use in clinical guideline development. Health Technol Assess. 1998;2(3):iiv, $1-88$.

11. Mkandawire N, Ngulube C, Lavy C. Orthopaedic clinical officer program in Malawi: a model for providing orthopaedic care. Clin Orthop Relat Res. 2008;466(10):2385-91. doi: 10.1007/s11999-0080366-5.

12. Gustilo RB, Anderson JT. Prevention of infection in the treatment of one thousand and twenty-five open fractures of long bones: Retrospective and prospective analyses. J Bone Joint Surg Am. 1976; 58:453-8.

13. Gustilo RB. Interobserver agreement in the classification of open fractures of the tibia. The results of a survey of two hundred and fortyfive orthopaedic surgeons. J Bone Joint Surg Am. 1995;77:1291-2.

14. Chokotho L, Mulwafu W, Singini I, Njalale Y, Jacobsen KH. Improving hospital-based trauma care for road traffic injuries in Malawi. World J Emerg Med. 2017;8(2):85-90. doi: 10.5847/ wjem.j.1920-8642.2017.02.001.

15. Ologunde R, Le G, Turner J, Pandit H, Peter N, Maurer D, et al. Do trauma courses change practice? A qualitative review of 20 courses in East, Central and Southern Africa. Injury. 2017;48(9):2010-6.

16. Gosselin RA, Roberts I, Gillespie WJ. Antibiotics for preventing infection in open limb fractures. Cochrane Database Syst Rev. 2004;(1):CD003764.

17. Jaeger M, Maier D, Kern WV, Sudkamp NP. Antibiotics in trauma and orthopedic surgery - a primer of evidence-based recommendations. Injury. 2006;37(Suppl 2):S74-80.

18. Khuluza F, Haefele-Abah C. The availability, prices and affordability of essential medicines in Malawi: A cross-sectional study. PLoS One. 2019;14(2):e0212125.

19. Gray KJ, Wilson LK, Phiri A, Corkill JE, French N, Hart CA. Identification and characterization of ceftriaxone resistance and extended-spectrum $\beta$-lactamases in Malawian bacteraemic Enterobacteriaceae. J Antimicrob Chemother. 2006;57(4):661-5.

20. OVIVA Trial Collaborators, Li HK, Rombach I, et al. Oral versus intravenous antibiotics for bone and joint infection. N Engl J Med. 2019;380(5):425-36.

21. Liddle C. Nil by mouth: best practice and patient education. Nurs Times. 2014;110(26):12-4.

22. Glass GE, Pearse MF, Nanchahal J. Improving lower limb salvage following fractures with vascular injury: a systematic review and new management algorithm. J Plast Reconstr Aesthet Surg. 2009;62:571-9.

23. Misra A, Nanchahal J. Use of gauze soaked in povidone iodine for dressing acute open wounds. Plast Reconstr Surg. 2003;111:2105-7.

24. Bowyer G. Debridement of extremity war wounds. J Am Acad Orthop Surg. 2006;14(Suppl):S52-6.

25. Park SH, Silva M, Bahk WJ, McKellop H, Lieberman JR. Effect of repeated irrigation and debridement on fracture healing in an animal model. J Orthop Res. 2002;20:1197-204.

26. Anglen JO. Wound irrigation in musculoskeletal injury. J Am Acad Orthop Surg. 2001;9:219-26.

27. Pollak AN, Jones AL, Castillo RC, Bosse M J, MacKenzie EJ \& LEAP Study Group. The relationship between time to surgical debridement and incidence of infection after open high-energy lower extremity trauma. J Bone Joint Surg Am. 2010;92(1):7-15.

28. Hendrickson SA, Wall RA, Manley O, Gibson W, Toher D, Wallis $\mathrm{K}$, et al. Time to Initial Debridement and wound Excision (TIDE) in severe open tibial fractures and related clinical outcome: A multi-centre study. Injury. 2018;49(10):1922-6. 
29. FLOW Investigators, Bhandari M, Jeray KJ et al. A Trial of wound irrigation in the initial management of open fracture wounds. N Engl J Med. 2015;373(27):2629-41. doi: 10.1056/NEJMoa1508502.

30. Fernandez R, Griffiths R. Water for wound cleansing. Cochrane Database Syst Rev. 2012;(2):CD003861.

31. Li MK, Howard DP, King R. "A picture tells a thousand words" smartphone-based secure clinical image transfer improves compliance in open fracture management. Injury. 2019;50(7):1284-7.

32. Gopal S, Majumder S, Batchelor A, Knight S, Boer PD, Smith R Fix and flap: the radical orthopaedic and plastic treatment of severe open fractures of the tibia. J Bone Joint Surg Br. 2000;82:959-66.

33. Ger R. Muscle transposition for treatment and prevention of chronic post-traumatic osteomyelitis of the tibia. J Bone Joint Surg Am. 1977;59:784-91.

34. Godina M. Early microsurgical reconstruction of complex trauma of the extremities. Plast Reconstr Surg. 1986;78:285-92.

35. Small JO, Mollan RA. Management of the soft tissues in open tibial fractures. Br J Plast Surg. 1992;45:571-7.

36. Naique SB, Pearse M, Nanchahal J. Management of severe open tibial fractures: the need for combined orthopaedic and plastic surgical treatment in specialist centres. J Bone Joint Surg Br. 2006;88:351-7.

37. Chokotho L, Jacobsen KH, Burgess D, Labib M, Le G, Peter $\mathrm{N}$, et al. A review of existing trauma and musculoskeletal impairment
(TMSI) care capacity in East, Central, and Southern Africa. Injury. 2016;47(9):1990-5.

38. Mock C, Cherian MN. The global burden of musculoskeletal injuries: challenges and solutions. Clin Orthop Relat Res. 2008;466(10):230616.

39. Chan Y, Banza L, Martin C Jr, Harrison WJ. Essential fracture and orthopaedic equipment lists in low resource settings: consensus derived by survey of experts in Africa. BMJ Open. 2018;8(9):e023473. doi: 10.1136/bmjopen-2018-023473.

40. Henry JA, Frenkel E, Borgstein E, Mkandawire N, Goddia C. Surgical and anaesthetic capacity of hospitals in Malawi: key insights. Health Policy Plan. 2015;30(8):985-94.

41. Bach O, Hope M, Chaheka C, Dzimbiri K. Disability can be avoided after open fractures in Africa-results from Malawi. Injury. 2004;35:846-51.

42. Lashoher A, Schneider EB, Juillard C, et al. Implementation of the World Health Organization trauma care checklist program in 11 centers across multiple economic strata: effect on care process measures. World J Surg. 2017;41(4):954-62.

43. White MC, Randall K, Capo-Chichi N, Sodogas F, Quenum S, Wright $\mathrm{K}$, et al. Implementation and evaluation of nationwide scale-up of the Surgical Safety Checklist. Br J Surg. 2019;106(2):e91-e102 . 


\section{ASSOCATION \\ MOA/AO Alliance Guidelines and Standards: open fracture management}

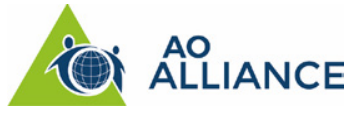

These guidelines are for all patients with open fractures of long bones, hind foot or midfoot (excluding hand, wrist, forefoot or digit). Grading refers to the Gustilo-Anderson classification.

1) Primary (A,B,C assessment) and secondary survey, according to ATLS/PTC, should precede the treatment of open fractures.

2) Intravenous prophylactic antibiotics should be administered as soon as possible and at least within 1 hour of presentation to the health facility:

a) Intravenous Ceftriaxone (at appropriate doses for age and weight)

b) Alternatively, oral Doxycline \& intravenous Gentamicin (if no Ceftriaxone is available)

c) For grossly contaminated wounds, in addition, administer intravenous Metronidazole

d) If none available, give the most appropriate available antibiotics

3) The examination of the injured limb should include assessment and documentation of the vascular and neurological status. This should be repeated systematically, particularly after reduction manoeuvres and/or the application of splints or casts.

4) Grade III C fractures with an ischaemic limb should be discussed immediately with the central hospital by telephone with a view to immediate referral when appropriate.

5) The limb must be re-aligned and splinted or casted before transfer to the ward or another health facility.

6) Prior to formal debridement the wound should be exposed only to remove gross contamination and to allow photography, then dressed with a sterile saline-soaked gauze.

7) Washouts outside the operating theatre environment are not indicated and patients should be prepared for debridement under spinal or general anaesthetic.

8) Debridement should be performed, under general or spinal anaesthetic, using fasciotomy lines for wound extension where possible:

a) Immediately for highly contaminated wounds (agricultural, aquatic, sewage) or when there is an associated vascular compromise (compartment syndrome or arterial disruption producing ischaemia).

b) Within 12 hours of presentation to hospital for grade II \& III fractures

c) Within 24 hours of presentation to hospital for grade I fractures

9) Before prepping and draping the patient, contamination is removed with at least $5 \mathrm{~L}$ of tap water. At debridement, all devitalised soft tissue and bone should be removed, both bone ends exposed, further irrigation with at least $2 \mathrm{~L}$ of sterile fluid.

10) Photographs of the wound should be taken at first presentation to the health facility and after debridement.

11) Once debridement is complete any further procedures (e.g. external fixation) carried out at that same sitting should be regarded as clean surgery; i.e. there should be fresh instruments and a re-prep and draping of the limb before proceeding.

12) a) Clean grade I fractures should be closed primarily

b) Grade II fractures should be left open and closed within 72 hours

c) Grade III A \& B fractures should be left open and referred to the nearest central hospital within 24 hours to enable wound closure or flap within 72 hours. This should include a letter and before \& after debridement photographs to the receiving surgeon

13) Long bone Grade III A \& B fractures should be stabilised with an external fixator at the time of debridement. In some cases, an orthopaedic surgeon may use internal fixation.

14) Definitive internal stabilisation should only be carried out when it can be immediately followed with definitive soft tissue cover. Approximation sutures over exposed bone should not be done.

15) Immediate amputation, except in life-threatening emergency, should not be undertaken without consultation with another surgical colleague.

16) Patients should receive explanation about their injury, the treatment and their functional outcome.

17) Written notes in the medical records should provide evidence of the application of these guidelines. 